\title{
OXYGEN INFLUENCE ON THE PROCESS OF NITROGEN-INDUCED PORE FORMATION IN CONSUMABLE ELECTRODE ARC WELDING*
}

\author{
V.A. PISAREV and S.N. ZHIZNYAKOV \\ Belarussian National Technical University \\ 65 Nezavisimost Ave., 220013, Minsk, Belarus Republic. E-mail: niil_svarka@bntu.by
}

\begin{abstract}
Nitrogen-induced porosity is one of the most common defects in welded joints produced by consumable electrode arc welding, particularly, in open sites. It is believed that in order to produce sound welds in low-carbon and low-alloyed steels, their nitrogen content should not exceed $0.01-0.03 \%$. At the same time, cases of producing tight welds at up to $0.18 \%$ nitrogen content are found in practice. This is indicative of the fact that alongside nitrogen concentration and temperature, other factors also have a determinant influence on the process of nitrogen-induced pore formation. One of such factors, as shown by the conducted analytical and experimental investigations, is oxygen present in weld pool metal. It is capable of slowing down penetration of nitrogen atoms from the melt into the gas cavity of developing nucleus or bubble (effect of oxygen adsorption inhibition). The newly established regularity was used in development of the technology of $\mathrm{CO}_{2}$ welding of steel structures in open sites under the impact of wind with the speed of up to $8-10$ m/s. 11 Ref., 1 Table, 1 Figure.
\end{abstract}

Keywords : arc welding, pores, nitrogen, adsorption inhibition, tight weld, technology

Standard technology of $\mathrm{CO}_{2}$ welding does not allow producing sound welded joints in open sites at wind speed above $2-3 \mathrm{~m} / \mathrm{s}$, as this leads to violation of gas shielding of the welding zone, into which atmospheric air penetrates in inadmissible quantities. This leads to formation of excess porosity, caused by nitrogen from the air.

Currently available $\mathrm{CO}_{2}$ welding methods, which allow the process to be conducted at wind speeds higher than $3 \mathrm{~m} / \mathrm{s}$, involve application of various wind-protection devices; special welding torches, improving gas-dynamic stability of shielding gas jet; with application of respective welding modes; welding wires alloyed with strong nitride-forming elements (Al, Ti, Zr, etc.).

For a number of reasons, however, the above welding methods and technologies did not become widely accepted in construction or in erection sites.

A rational way to solve the problem of increasing the scope of $\mathrm{CO}_{2}$ welding and, hence, raising the level of mechanization of welding operations in open areas, is searching for and development of a welding process, which would provide a real possibility of direct impact on nitrogen-induced pore formation mechanism proper, and, by controlling it, of slowing down pore formation.

\footnotetext{
${ }^{*}$ As a matter for discussion.

(C) V.A. PISAREV and S.N. ZHIZNYAKOV, 2016
}

For this purpose, it was, first of all, necessary to find an explanation of some of the known and contradictory facts, associated with nitrogen-induced pore formation:

- in arc welding in open air, porosity (by pore quantity and size) in welds, produced with wire of grade $\mathrm{Sv}-08$, is much smaller than that of welds made with wire of grade Sv-08G2S;

- in arc welding (surfacing) in an air jet with wire of grade Sv-08A with air flow rate of $301 / \mathrm{min}$, no pores form in welds. At the same time, at application of wire Sv-08G2S no tight welds are produced;

- in welding in a mixture of $\mathrm{CO}_{2}+4 \% \mathrm{~N}_{2}$ pores are absent. At the same time, in welding in a mixture of $\left(\mathrm{Ar}+20 \% \mathrm{CO}_{2}\right)+4 \% \mathrm{~N}_{2}$ welds have abundant porosity;

- in manual arc welding at increased arc length with rutile electrodes no pores form in welds, in welding with basic electrodes, providing better gas shielding of welding zone, considerable porosity is found in welds;

- in manual arc welding with chalk-coated electrodes, not providing sufficiently complete gas shielding of the welding zone from air, welds have no pores.

The above facts, given in the Table and in the Figure, complemented by information on nitrogen and oxygen content in weld metal, suggest the existence of the determinant influence of oxygen present in the melt on the process of formation of nitrogen-induced pores. 
Gas content and evaluation of pore formation in the metal of welds produced with different variants of welding zone protection from air

\begin{tabular}{|c|c|c|c|c|c|}
\hline \multirow{2}{*}{ \# } & \multirow{2}{*}{ Welding process and conditions } & \multicolumn{2}{|c|}{ Gas content, $\%$} & \multirow{2}{*}{ Porosity } & \multirow{2}{*}{$\begin{array}{c}\text { Information } \\
\text { source }\end{array}$} \\
\hline & & {$[\mathrm{N}]$} & {$[\mathrm{O}]$} & & \\
\hline 1 & $\mathrm{CO}_{2}$ welding, Sv-08G2S wire & 0.015 & 0.06 & No pores & Authors' data \\
\hline 2 & Welding in air, Sv-08G2S wire & 0.13 & 0.06 & Pores (coarse) & {$[1]$} \\
\hline 3 & Same, Sv-08 wire & 0.15 & 0.08 & Pores (fine) & [1] \\
\hline 4 & Welding in air jet (flow rate of $30 \mathrm{l} / \mathrm{min}$ ), Sv-08A wire & 0.18 & 0.13 & No pores & [1] \\
\hline 5 & Welding in mixture of $\mathrm{CO}_{2}+4 \% \mathrm{~N}_{2}$, Sv-08G2S wire & 0.03 & 0.07 & Same & Authors' data \\
\hline 6 & Welding in mixture of $\left(\mathrm{Ar}+20 \% \mathrm{CO}_{2}\right)+4 \% \mathrm{~N}_{2}$, Sv-08G2S wire & 0.04 & 0.03 & Pores & Same \\
\hline 7 & Manual short-arc welding, MR-3 electrodes & 0.02 & 0.08 & No pores & $»$ \\
\hline 8 & Same, with elongated arc & 0.04 & 0.08 & Same & $»$ \\
\hline 9 & Manual short-arc welding, UONII-13/55 electrodes & 0.02 & 0.02 & $»$ & $»$ \\
\hline 10 & Same, with elongated arc & 0.03 & 0.02 & Pores & $»$ \\
\hline 11 & Manual arc welding, electrodes with chalk coating & 0.14 & 0.13 & No pores & [2] \\
\hline
\end{tabular}

Note. It is believed [1] that in welding of low-carbon and low-alloyed steels, pores in weld metal in the general case form at nitrogen content above $0.01-0.03 \%$ in it.

Detailed analysis of the derived data clearly demonstrates that with increase of dissolved oxygen concentration nitrogen-induced pore formation threshold rises abruptly.

Evolution of gases dissolved in the metal into an independent phase primarily requires availability of nucleation centers (nuclei) of gas bubbles in the melt. Probable sites of nucleus formation are present in the weld pool various kinds of microvoids, solid non-metallic inclusions poorly wetted by the metal and other suspensions contained in the melt. Some researchers $[1,3]$, and also the authors of this paper, believe that pore nuclei in arc welding of low-carbon and low-al-

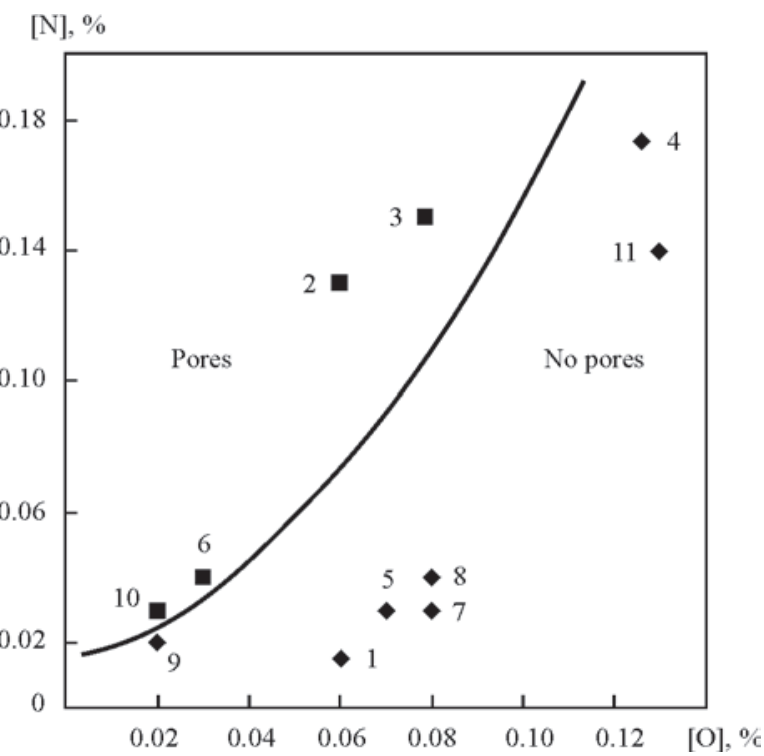

Influence of oxygen content on formation of nitrogen-induced pores in welds produced in consumable electrode arc welding of low-carbon and low-alloyed steels (1-11 - acc. to the Table) loyed steels are caused predominantly by the reaction of carbon oxide formation.

Subsequent development of a nucleus and its transformation into a gas bubble, after achievement of critical radius, as well as further bubble growth up to visible dimensions, and its transition into a pore at weld pool metal solidification, can occur under the impact of both continuing formation of carbon oxide and evolving from the surrounding volume of liquid metal hydrogen and nitrogen - gases present in oversaturated state in the melt.

There is an opinion $[1,4]$ that weld metal proneness to pore formation can be theoretically assessed by the total latent partial pressure of gases capable of evolving from the metal as a result of reactions running under equilibrium conditions. Here, pores (more correctly, bubbles) are capable of appearing, when the latent total pressure of gases $\Sigma P_{1}$ (carbon, hydrogen and nitrogen oxides) will be noticeably higher than external pressure $P_{\mathrm{ex}}$, which can be conditionally taken equal to $0.1 \mathrm{MPa}$.

However, the data given in the Table and practical experience of welding operations performance, point to the fact that such an approach to evaluation of the role of all or one of the gases in pore formation needs to be precisely refined. So, actual participation of nitrogen in pore formation, in particular, in welding in oxidizing medium, cannot be determined unambiguously by calculation through determination of latent partial pressure of gases present in the weld pool. The latter is due to the fact that in this case behaviour of nitrogen dissolved in liquid steel does not follow the Sieverts square root law, establishing the dependence 
between gas concentration in liquid metal and its partial pressure.

According to this law, at nitrogen content in the metal equal to 0.14 and $0.18 \%$, its calculated partial pressures in gas cavity of the bubbles should approach 12 and $20 \mathrm{MPa}$, respectively, that, as a consequence, should cause extremely large porosity, according to the above opinion. However, in reality, even at such high nitrogen contents porosity in weld metal is absent (see the Table), and, therefore, partial pressures of nitrogen in the bubbles (or developing nuclei) do not exceed $0.1 \mathrm{MPa}$. The cause for this phenomenon, as was established by experimental and analytical investigations, is the high content of oxygen of $0.13 \%$ in the weld pool. Thus, qualitative assessment of appearance of gas bubbles, which are the precursors of pores induced by nitrogen, requires not only knowledge of concentrational and temperature parameters of nitrogen dissolved in the metal, but also understanding of the specifics of the influence of oxygen contained in the melt, as one of strong surfactants, on pore formation process.

Analysis of published data on the issues of gases absorption and evolution from the weld pool and pore formation in weld metal made by arc welding, familiarization with diffusion of gases in metal melts and with the processes of liquid metal degassing in steel production [1-10] suggested the following path of nitrogen penetration into the developing nucleus or growing bubble (furtheron - bubble), consisting of the following four stages.

First stage. Transfer by means of convective diffusion (convective and diffusion processes are involved in transfer) of atoms of nitrogen dissolved in weld pool metal to metal-bubble gas phase interface.

Owing to high temperature of molten metal and presence in the weld pool in consumable electrode arc welding, of convective metal flows, moving continuously at the speed, which is by 10 to 20 times higher than welding speed [6], and continuously washing the surface of the growing and floating bubble, nitrogen atoms approach the interface with a high intensity.

Second stage. Adsorption of nitrogen atoms by surface layer of liquid metal on metal-bubble gas phase interface.

Simultaneously with nitrogen, other gases dissolved in weld pool metal are brought to the interface (surface layer), including (and this is particularly important) oxygen, which is characterized by high diffusion mobility and is always present in the metal melt. Here, atoms of oxygen, which is a strong surfactant, according to Gibbs (adsorption) law are adsorbed by the surface layer, taking up in it, on a priority basis, the part of free adsorption sites (centers), correspond- ing to their concentration, and partially also the sites occupied by nitrogen atoms, driving the latter away from the interface. This reduces the fraction of sites, potentially capable of adsorbing the atoms of nitrogen, also having surface-active properties, even though to a much smaller degree.

Reduction of adsorption sites vacant for nitrogen, reduces adsorption rate and, hence, the coefficient of mass transfer of nitrogen atoms across metal-bubble gas phase interface that may be assessed by the following expression: $v_{\text {ads }}=K C(1-\alpha)$, where $K$ is the coefficient of proportionality; $C$ is the nitrogen concentration in the weld pool; $\alpha$ is the fraction of adsorption sites taken up by oxygen on the interface, determined by its content in the metal melt.

At low content of oxygen in weld pool metal of not more than $0.01-0.03 \%$, when the fraction of adsorption sites $\alpha$ taken up by oxygen is extremely small, a high proneness of weld metal to formation of nitrogen-induced pores (argon-arc welding, welding in a mixture of $\mathrm{CO}_{2}+\mathrm{Ar}$, manual basic-electrode arc welding) is in place. A noticeable increase of resistance to pore formation is observed at oxygen content in the weld pool of the order of $0.07-0.11 \%$. In this case, oxygen atoms take up a considerable part of the interface, that reduces the rate of nitrogen atom adsorption and facilitates producing tight welds in manual arc welding with rutile or acid electrodes by an elongated arc and in open air at high wind speed, as well as in $\mathrm{CO}_{2}$ welding with bleeding up to $4 \%$ nitrogen or up to $6 \%$ air into the welding zone.

At higher concentration of oxygen in the melt (above $0.11-0.13 \%$ ) its atoms are, apparently, capable of taking up the entire interface $(\alpha=1)$, and even forming in the surface layer chemical groups of composition close to that of iron oxide. Such a layer practically stops atom transition across the interface, and bubble development does not proceed even at very high content (high degree of oversaturation) of nitrogen in the weld pool $(0.14-0.18 \%)$. This exactly can be the explanation for absence of visible porosity in welding in an air jet with $\mathrm{Sv}-08 \mathrm{~A}$ wire at air flow rate of $30 \mathrm{l} / \mathrm{min}$ (weld pool metal is further oxidized due to participation of oxygen from the air in the metallurgical process), as well as in welding with chalk-coated electrodes.

An event takes place, which can be defined as the effect of oxygen adsorption inhibition of the process of nitrogen-induced pore formation.

Third stage - molization of adsorbed nitrogen atoms. Physically adsorbed nitrogen atoms, present in the surface layer, enter into chemical interaction with formation of molecules with highly stable three covalent bonds: $2 \mathrm{~N}_{\mathrm{ads}}=\mathrm{N}_{2}$. Here, a large amount $(945 \mathrm{~kJ} /$ 
mol) of thermal energy evolves (energy of molization activation is just $0.4 \mathrm{~kJ} / \mathrm{mol}$ ).

Fourth stage - desorption of formed nitrogen molecules into the bubble gas cavity. Under the conditions of high temperature of molten metal and low partial pressure of nitrogen in the gas cavity, desorption of nitrogen molecules is limited, mainly, by the intensity of nitrogen atom mass transfer across the interface, determined by nitrogen concentration and oxygen content in weld pool metal.

Thus, and this very clearly follows from the above material, one of the main factors, determining the process of formation of nitrogen-induced pores in consumable electrode arc welding of low-carbon and low-alloyed steels, also is the specific impact of oxygen contained in weld pool metal, that may be used as an effective regulator of pore formation mechanism.

The postulate and its consequence - the effect of oxygen adsorption inhibition - were taken as the metallurgical basis in development of $\mathrm{CO}_{2}$ welding technology, providing sound welded joints in open construction and assembly sites at wind speed of up to $8-10 \mathrm{~m} / \mathrm{s}$, when the welding zone is «enriched» by atmospheric air. In order to increase oxygen content in the melt up to a moderate rational level of $0.07-$ $0.09 \%$, application of wire with minimum admissible content of deoxidizer elements and of gas mixture of carbon dioxide gas with oxygen having a higher oxidizing ability, compared to pure carbon dioxide gas, was successfully tried out [11]. The influence of gases contained in weld metal on mechanical properties of welded joints was taken into account.

\section{Conclusions}

1. Oxygen contained in weld pool metal has a significant influence on the process of formation of nitro- gen-induced pores in consumable electrode arc welding of low-carbon and low-alloyed steels. It directly influences the mechanism of nitrogen atoms (molecules) penetration into the gas cavity of the developing nucleus and growing bubble, blocking the process of pore formation (effect of oxygen adsorption inhibition).

2. Increase of oxygen concentration in the melt is capable of greatly reducing the proneness of weld metal to formation of nitrogen-induced porosity. This phenomenon was successfully used in development of the technology of $\mathrm{CO}_{2}$ welding of steel structures in open air at wind speed of 8-10 m/s.

1. Novozhilov, N.M. (1979) Principles of metallurgy of gas-shielded arc welding. Moscow: Mashinostroenie.

2. Alov, A.A. (1947) Electrodes for arc welding and surfacing. Moscow: Mashgiz.

3. Alov, A.A. (1969) Principles of theory of welding and brazing processes. Moscow: Mashinostroenie.

4. Pokhodnya, I.K. (2004) Metallurgy of arc welding. Interaction of metals with gases. Moscow: Mashinostroenie.

5. Ershov, G.S., Majboroda, V.P. (1990) Diffusion in metallurgical melts. Kiev: Naukova Dumka.

6. Erokhin, A.A. (1973) Principles of fusion welding. Moscow: Mashinostroenie.

7. Konishchev, B.P., Kurlamov, S.A., Potapov, N.N. et al. (1989) Welding consumables for arc welding. Shielding gases and welding fluxes, Vol. 1. Moscow: Mashinostroenie.

8. (1993) Welding consumables for arc welding. Welding wire and electrodes, Vol. 2. Moscow: Mashinostroenie.

9. Kudrin, V.A. (2003) Theory and technology of steel making: Manual. Moscow: Mir.

10. Rimsky, S.T. (2008) Methods for increase of weld metal resistance to crack formation in shielded-gas arc welding. Svarshchik v Belorussii, 4, 15-18.

11. Zhiznyakov, S.N., Timalev, L.N. (1977) Influence of oxygen on welding process in $\mathrm{CO}_{2}+\mathrm{O}_{2}$ mixture. Svarochn. Proizvodstvo, 2, 25-27. 